\title{
Valve-sparing neo-aortic root replacement after Fontan completion for hypoplastic left heart syndrome
}

\author{
Christian Pizarro, MD, ${ }^{\mathrm{a}}$ Jeanne M. Baffa, MD, ${ }^{\mathrm{a}}$ Christopher D. Derby, MD, ${ }^{\mathrm{a}}$ and Portia A. Krieger, MD, ${ }^{\mathrm{b}}$ \\ Wilmington, Del
}

Development of neo-aortic root dilatation is a well-known entity among patients with congenital heart defects in whom the native pulmonary root is placed in the systemic position. ${ }^{1,2}$ Patients undergoing a Norwood procedure constitute no exception. Valve-sparing aortic root replacement, a procedure commonly utilized to treat aortic root dilatation among patients with connective tissue disorders, can be an effective form of therapy for this condition.

\section{CLINICAL SUMMARY}

A 10-year-old patient status post-Fontan completion for hypoplastic left heart syndrome (HLHS) (aortic atresia, mitral atresia) demonstrated progressive neoaortic (native pulmonary) root dilatation during follow-up. A computed tomographic scan of the chest revealed an aortic root aneurysm with a diameter of $5.4 \mathrm{~cm}$ at the level of the sinuses of Valsalva (z-score 12, based on normative data for native aortas). Although the neo-aortic valve remained competent, near complete obliteration of the left pulmonary artery by the expanding aortic root was seen (Figure 1).

A valve-sparing neo-aortic root replacement was performed with a 30-mm Valsalva graft (Terumo; Cardiovascular Systems Corporation, Ann Arbor, Mich). Cardiopulmonary bypass with moderate hypothermia was utilized. Venous return was established via single venous cannula in the pulmonary venous atrium while maintaining ventilation to facilitate blood flow across the pulmonary vascular bed. Following cardioplegic arrest, direct inspection revealed a bicuspid native pulmonary valve with an annulus measuring $34 \mathrm{~mm}$ (Figure 2, A). The amalgamation between the native ascending aorta and main pulmonary artery was taken down, and the aneurysmal portion of the root, as well as the ascending aorta were excised, leaving $2 \mathrm{~mm}$ of native tissue at the base of the sinuses of Valsalva. The graft was anchored around the pulmonary root with su-

\footnotetext{
From the Nemours Cardiac Center, ${ }^{\mathrm{a}}$ Division of Diagnostic Pathology, ${ }^{\mathrm{b}}$ Alfred I. duPont Hospital for Children, Wilmington, Del.

Disclosures: Authors have nothing to disclose with regard to commercial support. Received for publication May 14, 2010; revisions received June 27, 2010; accepted for publication July 31, 2010; available ahead of print Sept 29, 2010.

Address for reprints: Christian Pizarro, MD, Nemours Cardiac Center, Alfred I. du-

Pont Hospital for Children, 1600 Rockland Road, Wilmington, DE 19803

(E-mail: cpizarro@nemours.org).

J Thorac Cardiovasc Surg 2011;141:1083-4

$0022-5223 / \$ 36.00$

Copyright (c) 2011 by The American Association for Thoracic Surgery

doi:10.1016/j.jtcvs.2010.07.076
}

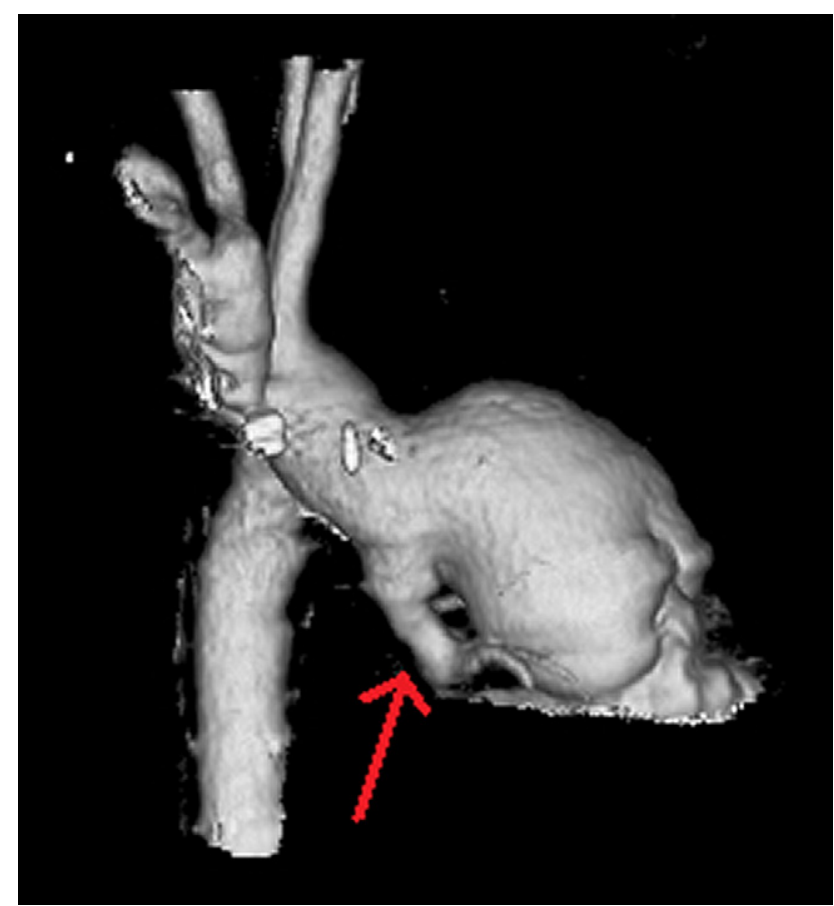

FIGURE 1. Computed tomographic angiogram reconstruction illustrating the aneurysmal involvement of the neo-aorta mainly at the expense of the native proximal main pulmonary artery. (Red arrow shows the native aorta.)

tures placed under the nadir of each leaflet. A suture line was constructed following the contour of the valve apparatus between the cuff of native tissue and the graft. The commissures were suspended at the appropriate height and valve competency was restored (Figure 2, B). The native ascending aorta was "reimplanted" separately on the rightward aspect of the graft (Figure 2,C). The presence of a well-defined "neck," allowed the distal anastomosis to be performed proximal to the aortic cross-clamp.

Transesophageal echocardiogram revealed normal ventricular function and trace neo-aortic insufficiency. One year later, the patient remains in excellent condition with a completely competent neo-aortic valve.

Histologic analysis demonstrated no evidence of inflammation but rather fragmentation and loss of elastic fibers, deposition of myxoid material, and loss of smooth muscle cells in the media, findings commonly seen in cases of aortopathy associated with bicuspid aortic valves and connective tissue disorders. 

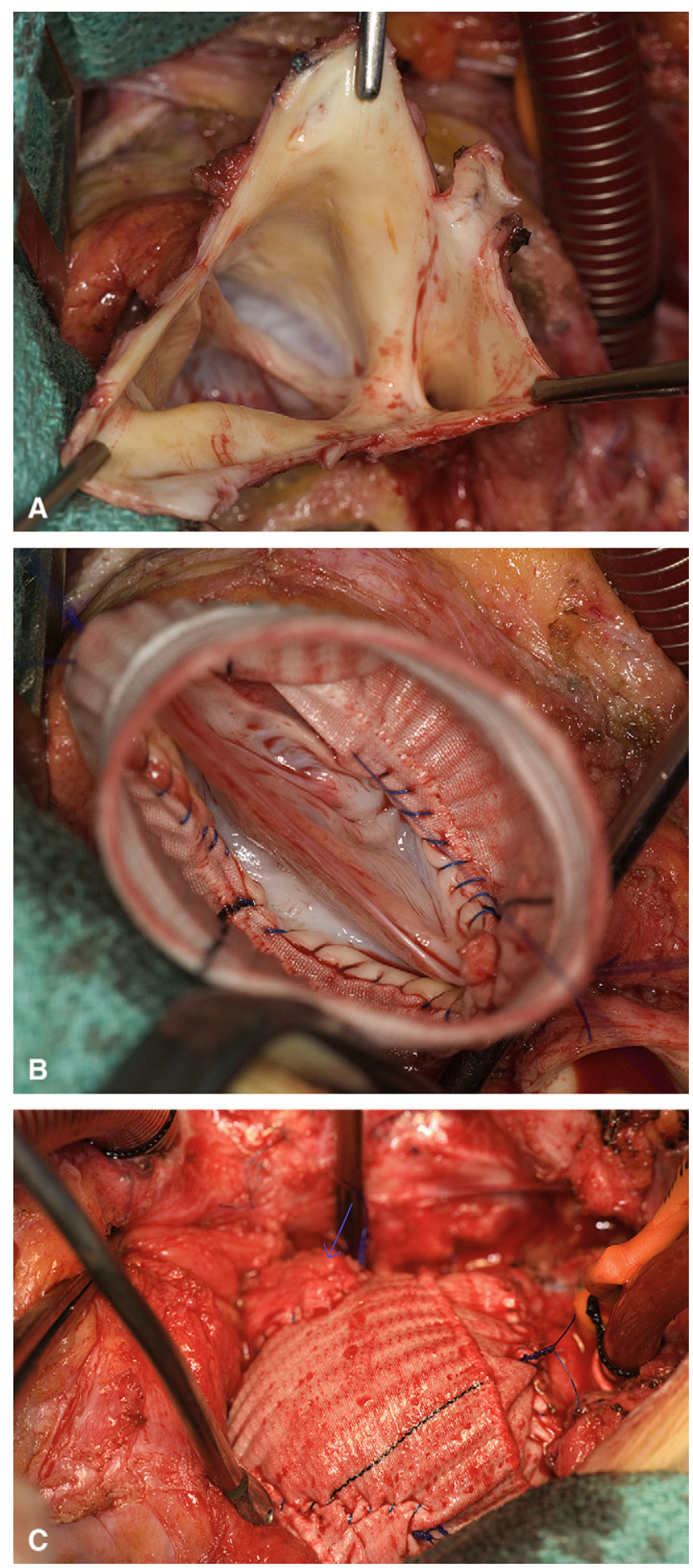

FIGURE 2. A, Operative view of the dilated neo-aortic root. Note the true bicuspid native pulmonary valve. Smaller lumen on the right corresponds to the native ascending aorta. B, Operative view after excision of the aneurysm and reimplantation of the pulmonary valve into the graft. Hemostatic suture line between the graft and the 2-mm cuff off tissue at the base of each sinus. $\mathrm{C}$, Neoascending aorta replaced. The native ascending aorta (arrow) reimplanted as a separate button on the rightward aspect of the aorta.

\section{DISCUSSION}

Neoaortic root dilatation is a common and progressive disorder affecting survivors of staged palliation for HLHS. $^{3}$ Valve-sparing neo-aortic root replacement can provide an effective and durable solution, particularly if valve incompetence or extrinsic compression of the adjacent pulmonary arteries exists. Although technically more demanding than replacing the aorta above the sinotubular junction, ${ }^{4,5}$ the valve-sparing inclusion technique is necessary to eliminate all the affected tissue and to provide circumferential support below the valve annulus, thus eliminating the potential for recurrent root dilatation and neoaortic valve regurgitation associated with it.

Semilunar valve regurgitation and the type of material used during the arch reconstruction have been linked to the development of neo-aortic root aneurysm in this population. ${ }^{5}$ However, the absence of the former and the involvement of the pulmonary root proximal to the homograft reconstruction suggests a different mechanism for aneurysm development. In this case it could be linked to the arterial wall pathology associated with a bicuspid valve or the exposure of the native pulmonary root to systemic pressures, as reported among survivors of arterial switch or Ross procedures. ${ }^{1,2}$

In the absence of outcome data, the extensive nature of this surgery with a potential for significant morbidity make the indications for surgical intervention uncertain and this is still largely based on experience with aneurysmal disease associated with connective tissue disorders. In the presence of a Fontan circulation, compression of the central pulmonary arteries by the expanding aneurysm has important hemodynamic implications and should be factored in this decision.

Although valve-sparing neo-aortic root replacement offers an effective and potentially durable solution, natural history and operative risk data are necessary to better define the management of these patients.

\section{References}

1. Lalezari S, Hazekamp MG, Bartelings M, Schoof PH, Gittenberger-de Groot AC. Pulmonary artery remodeling in transposition of the great arteries: relevance for neoaortic root dilatation. J Thorac Cardiovasc Surg. 2003;126: 1053-60.

2. Luciani GB, Casali G, Favaro A, Prioli MA, Barozzi L, Santini F, et al. Fate of the aortic root late after Ross operation. Circulation. 2003;108(Suppl II): II61-7.

3. Cohen MS, Marino BS, McElhinney DB, Robbers-Visser D, van der Woerd W, Gaynor JW, et al. Neo-Aortic root dilatation and valve regurgitation up to 21 years after staged reconstruction for hypoplastic left heart syndrome. J Am Coll Cardiol. 2003;42:533-40

4. Patel ND, Williams JA, Barreiro CJ, Bethea BT, Fitton TP, Dietz HC, et al. Valvesparing aortic root replacement: early experience with the De Paulis Valsalva graft in 51 patients. Ann Thorac Surg. 2006;82:548-53.

5. Shuhaiber JH, Patel V, Husayni T, El-Zein C, Barth MJ, Ilbawi MN. Repair of symptomatic neoaortic aneurysm after third-stage palliation for hypoplastic left heart syndrome. J Thorac Cardiovasc Surg. 2006;131:478-9. 